\title{
Targeting the oncogene LSF with either the small molecule inhibitor FQI1 or siRNA causes mitotic delays with unaligned chromosomes, resulting in cell death or senescence
}

Jennifer L. S. Willoughby ${ }^{1,2}$, Kelly George ${ }^{3}$, Mark P. Roberto ${ }^{2}$, Hang Gyeong Chin ${ }^{4,5}$, Patrick Stoiber ${ }^{2,4}$, Hyunjin Shin ${ }^{6}$, Chandra Sekhar Pedamallu ${ }^{7,8}$, Scott E. Schaus ${ }^{9}$, Kevin Fitzgerald ${ }^{1}$, Jagesh Shah ${ }^{3}$ and Ulla Hansen ${ }^{2,4^{*}}$ (D)

\begin{abstract}
Background: The oncogene LSF (encoded by TFCP2) has been proposed as a novel therapeutic target for multiple cancers. LSF overexpression in patient tumors correlates with poor prognosis in particular for both hepatocellular carcinoma and colorectal cancer. The limited treatment outcomes for these diseases and disappointing clinical results, in particular, for hepatocellular carcinoma in molecularly targeted therapies targeting cellular receptors and kinases, underscore the need for molecularly targeting novel mechanisms. LSF small molecule inhibitors, Factor Quinolinone Inhibitors (FQIs), have exhibited robust anti-tumor activity in multiple pre-clinical models, with no observable toxicity.

Methods: To understand how the LSF inhibitors impact cancer cell proliferation, we characterized the cellular phenotypes that result from loss of LSF activity. Cell proliferation and cell cycle progression were analyzed, using HeLa cells as a model cancer cell line responsive to FQI1. Cell cycle progression was studied either by time lapse microscopy or by bulk synchronization of cell populations to ensure accuracy in interpretation of the outcomes. In order to test for biological specificity of targeting LSF by FQI1, results were compared after treatment with either FQI1 or siRNA targeting LSF.

Results: Highly similar cellular phenotypes are observed upon treatments with FQI1 and siRNA targeting LSF. Along with similar effects on two cellular biomarkers, inhibition of LSF activity by either mechanism induced a strong delay or arrest prior to metaphase as cells progressed through mitosis, with condensed, but unaligned, chromosomes. This mitotic disruption in both cases resulted in improper cellular division leading to multiple outcomes: multinucleation, apoptosis, and cellular senescence.

(Continued on next page)
\end{abstract}

\footnotetext{
* Correspondence: uhansen@bu.edu

${ }^{2}$ Department of Biology, Boston University, 5 Cummington Mall, Boston, MA

02215, USA

${ }^{4}$ MCBB Graduate Program, Boston University, Boston, MA 02215, USA

Full list of author information is available at the end of the article
}

C C The Author(s). 2020 Open Access This article is licensed under a Creative Commons Attribution 4.0 International License, which permits use, sharing, adaptation, distribution and reproduction in any medium or format, as long as you give appropriate credit to the original author(s) and the source, provide a link to the Creative Commons licence, and indicate if changes were made. The images or other third party material in this article are included in the article's Creative Commons licence, unless indicated otherwise in a credit line to the material. If material is not included in the article's Creative Commons licence and your intended use is not permitted by statutory regulation or exceeds the permitted use, you will need to obtain permission directly from the copyright holder. To view a copy of this licence, visit http://creativecommons.org/licenses/by/4.0/. The Creative Commons Public Domain Dedication waiver (http://creativecommons.org/publicdomain/zero/1.0/) applies to the data made available in this article, unless otherwise stated in a credit line to the data. 


\begin{abstract}
(Continued from previous page)
Conclusions: These data strongly support that cellular phenotypes observed upon FQl1 treatment are due specifically to the loss of LSF activity. Specific inhibition of LSF by either small molecules or siRNA results in severe mitotic defects, leading to cell death or senescence - consequences that are desirable in combating cancer. Taken together, these findings confirm that LSF is a promising target for cancer treatment. Furthermore, this study provides further support for developing FQls or other LSF inhibitory strategies as treatment for LSF-related cancers with high unmet medical needs.
\end{abstract}

Keywords: LSF, FQI1, Small molecule inhibitors, siRNA, Mitosis, Senescence

\section{Background}

LSF (encoded by TFCP2) is an evolutionarily conserved transcription factor that is normally expressed ubiquitously at low levels, but is significantly overexpressed in multiple specific cancers [1]. This was initially shown in hepatocellular carcinoma cell lines and patient samples, in which levels of LSF in patient samples from multiple populations rise with increased stage and severity of disease [2-5]. Furthermore, LSF is oncogenic for hepatocellular carcinoma, as it is sufficient to promote hepatocellular carcinoma tumor growth in mouse xenograft models [2, 3]. In both colorectal cancer and hepatocellular carcinoma, patients with elevated LSF levels have significantly worse prognosis, with shorter median disease-free survival times than those with low LSF levels $[4,6]$. Finally, recent reports demonstrated that LSF can function as a coactivator for key transcription factors downstream of the Hippo and Wnt signaling pathways - YAP [5] and $\beta$ catenin [7] - both of which are widely accepted to contribute to liver proliferation and oncogenesis, as well as other cancer types.

Primary liver cancer and colorectal cancer are among the most common cancers worldwide (sixth and third, respectively), and represent leading causes of cancer mortality (second and fourth, respectively) [8-10]. Hepatocellular carcinoma represents approximately $70-80 \%$ of primary liver cancer cases $[9,11]$. Although treatment options have improved, survival rates have only moderately increased. The two initial first-line FDA-approved therapies for late-stage hepatocellular carcinoma, Sorafenib and Regorafenib (multi-kinase inhibitors), demonstrate only modest improvement in patient survival rates $[12,13]$, and result in significant side effects and rapid development of drug resistance. A recent additional first-line treatment for unresectable hepatocellular carcinoma approved by the FDA, lenvatinib, demonstrates improvements in progression-free survival and objective response rate, although still limited improvement in survival [14]. Thus, a large unmet medical need remains for hepatocellular carcinoma, as well as colorectal patient populations. Therapies directed to distinct molecular targets, ideally to which the cancer is oncogene addicted, have been promoted for mitigating these cancers [11].
A family of small molecule inhibitors of LSF, Factor Quinolinone Inhibitors (FQIs), was identified that inhibits the DNA binding and transcription activity of LSF, but not that of transcription factors from multiple other structural classes [15]. Phenotypically, depletion of LSF by siRNA or FQIs inhibit growth of hepatocellular carcinoma or pancreatic cells in vitro $[2,5,7,15]$. They also inhibit hepatocellular carcinoma tumor growth in vivo in multiple mouse models, including a mouse endogenous liver tumor model [16]. In all cases, inhibition of tumor growth occurred in the absence of toxicity, as assessed by liver injury markers, histopathology of tissues with rapid cell turnover, or blood cell counts [17]. These results suggested that hepatocellular carcinoma cells are oncogene addicted to LSF $[15,18]$.

Oncogenic transcription factors are promising therapeutic targets given that they regulate tumorigenic pathways. However, transcription factors, in general, have been notoriously difficult to target with small molecule inhibitors as their DNA binding domains are commonly small and the proteins themselves are intrinsically disordered, a feature allowing promiscuity in binding partners [19]. Identification of the transcription factor LSF as an oncogene and the significant inhibition of tumor growth upon LSF inhibition with no observed toxicity indicate that LSF holds considerable promise as a cancer therapeutic target $[2,15,20]$. Targeting a transcription factor has been challenging, therefore validation of the biological specificity of the LSF inhibitors is essential. Here we demonstrate that molecular and phenotypic consequences of knockdown of LSF with a specific siRNA are highly similar to those upon treatment of cells with FQI1, therefore confirming that FQIs are indeed specific in targeting this transcription factor.

The molecular mechanisms by which LSF promotes cancer cell survival have not been characterized in detail, although initial data indicated that FQIs induce a mitotic arrest in hepatocellular carcinoma cells [16]. Clarifying the pathways by which inhibition of LSF leads to cell death is important to support the candidacy of FQIs as a molecular therapy. Cell cycle analysis by flow cytometry and time-lapse microscopy revealed mitotic defects including mitotic delays with condensed, but unaligned 
chromosomes, leading to increased time in mitosis, defective cell division, multi-nucleation, and apoptosis. In addition, loss of LSF activity induced senescence in a sub-population of cells in a dose-dependent manner. Senescence, as well as mitotic arrest and apoptosis, are all desirable outcomes for a cancer chemotherapeutic.

\section{Methods}

\section{Preparation of FQI1}

FQI1 was synthesized as previously described [15]. FQI1 was dissolved in analytical grade DMSO (Sigma). The final DMSO concentration added to the cells was $0.5 \%$.

\section{Cell lines and synchronization}

HeLa cells (gift from Devanand Sarkar, Virginia Commonwealth University) were cultured at $37^{\circ} \mathrm{C}$ in $10 \%$ $\mathrm{CO}_{2}$ in DMEM (Corning Cellgro) supplemented with 10\% Fetal Bovine Serum (FBS; Atlanta Biologicals). Validation of HeLa cells was performed both by PCR of genomic DNA to confirm presence the E7 region of HPV18 and RNA-seq analysis to confirm expression of the precise regions of the HPV18 genome that are known to be present in HeLa cells. Cells tested negative for mycoplasma genus by PCR (Charles River Research). After thawing, cells underwent no more than 9 passages prior to harvesting. For synchronization using a double thymidine block protocol, cells were treated with $2 \mathrm{mM}$ thymidine (Sigma) in complete medium for $18 \mathrm{~h}$, and then released into complete medium for $6 \mathrm{~h}$ followed by incubation in $2 \mathrm{mM}$ thymidine in complete medium for a second 18-h incubation. For release from the G1/S block, cells were transferred into complete medium. The single thymidine block involved a single $24 \mathrm{~h}$ incubation in $2 \mathrm{mM}$ thymidine and release into complete media. As indicated, the release medium also contained $20 \mu \mathrm{M}$ of thymidine. The single thymidine protocol generates partially synchronized cell populations for time lapse experiments, with cells generally retaining full ability to progress through mitosis upon release from the block (Additional file 1).

\section{siRNA transfection}

siRNAs were designed and synthesized at Alnylam Pharmaceuticals, Inc. siRNA sequences used: LSF Sense: 5' GUGUGAUGUUUAACAGGAATT 3'; LSF Antisense: 5' UUCCUGUUAAACAUCACACTT $3{ }^{\prime}$; LBP1A Sense 5' UUUCAGGUGCCGACUUAUUTT 3'; LBP1A Antisense: 5' AAUAAGUCGGCACCUGAAATT 3'. The siRNAs were stabilized using certain chemical modifications as previously described allowing durable knockdown [21, 22]. The siRNA control was a sequence targeting RNA encoding firefly luciferase and was, therefore, non-targeting in the cells utilized for these studies. Cells were transfected using RNAimax (Life Technologies) according to manufacturer's instructions. Transfection efficiency was measured by fluorescent microscopy $24 \mathrm{~h}$ post transfection by cellular uptake of the Cy3 labeled control siRNA, and was determined to be $>90 \%$. For all siRNA experiments, the initial thymidine block was started $24 \mathrm{~h}$ after transfection of the siRNA.

\section{Time-lapse microscopy}

In order to image cell cycle progression for HeLa cells, retroviral Packaging Cells (GP2-293; Clontech) were transfected with pVSV-G (Clontech) and a pBABE vector containing both a gene for YFP-tagged histone $\mathrm{H} 2 \mathrm{~B}$ protein (H2B-YFP) and for a gene encoding G418 resistance. The virus-containing supernatant was collected for transduction of HeLa cells and the population of resistant cells was selected with G418 (Gibco).

For time-lapse microscopy of siRNA-treated cells, the HeLa cells expressing H2B-YFP were transfected and synchronized with a single thymidine block and release. After release, cells were imaged in $\mathrm{CO}_{2}$ independent medium (Leibovitz's L-15 without phenol red) on a Nikon TA10 Eclipse with a $20 \mathrm{X}$ objective at $37^{\circ} \mathrm{C}$. For time-lapse microscopy of FQI1-treated cells, asynchronous HeLa cells expressing H2B-YFP were treated with either vehicle or $0.9,1.8$, or $3.6 \mu \mathrm{M}$ FQI1 in $\mathrm{CO}_{2}$ independent medium (Leibovitz's L-15 without phenol red). Cells were imaged immediately on a Nikon TA10 Eclipse with a $20 \mathrm{X}$ objective at $37^{\circ} \mathrm{C}$. Images were acquired every $4 \mathrm{~min}$ at 7-10 positions per sample, over a five- to eleven-hour time span. Length of mitosis was measured from nuclear envelope breakdown to anaphase. Nuclear envelope breakdown was identified as the first image displaying disordered, condensed chromosomes. Anaphase was identified as the first image showing sister chromatid separation (for normal anaphases) or showing a furrow beginning to form over the chromosomes. For experiments, 100 to 101 cells were examined per condition.

\section{Cell flow cytometry}

Cells were harvested, combining non-attached cells in the media with cells on the dishes for centrifugation, washing prior to a second centrifugation, and fixing the resuspended cells with ethanol. All reagents were cold, to limit further cell cycle progression during these procedures. Cells were stained with the Guava cell cycle reagent (EMD Millipore) according to manufacturer's instructions. Fluorescence was analyzed on a BD Dickenson FACS Calibur.

\section{Immunoblotting}

At various time points, cells were harvested. When extracts were prepared specifically to analyze cells in mitosis, cells were visually examined prior to the 
anticipated time of mitotic entry, and were only harvested once control cells rounded, in order to compensate for fluctuations in the precise timing of mitotic entry from one batch of cells to another. Cells were lysed in RIPA buffer (125 mM Tris $\mathrm{HCl}, 150 \mathrm{mM} \mathrm{NaCl}$, $0.1 \%$ NP-40, 1.0\% sodium deoxycholate, 1.0\% SDS, pH 7.6) containing ROCHE protease cocktail phosphatase inhibitors (Sigma Aldrich 4,693,159,001) at the manufacturer's recommended concentrations. Lysates were electrophoresed through 4-20\% Mini-PROTEAN ${ }^{\circ}$ TGX $^{\mathrm{mm}}$ Precast gradient gels (Bio-Rad). The proteins were transferred to a PVDF membrane, and membranes were incubated for $1 \mathrm{~h}$ in Odyssey Blocking buffer (LI-COR Biosciences cat\# 927-40,000). Primary antibodies included Aurora Kinase B (Abcam AB2254), Cdc20 (Abcam AB26483), Cyclin B1 (Abcam AB72), LBP-1A (Millipore Sigma ABE181), LSF (Millipore Sigma ABE180), phosphorylated Histone 3 Serine 10 (Abcam ab5176), $\beta$-actin (Sigma A3853, A2066, and A2228), and $\alpha$-Tubulin (Sigma, 10,002). Secondary antibodies were from LI-Cor, Inc. and included donkey anti-mouse IR800 (926-32,212), donkey anti-rabbit IR800 (926-32, 213), goat anti-rabbit IR680 $(926-68,073)$, and goat antimouse IR680 (926-32,214). PVDF membranes were imaged using the LI-COR Odyssey [23]. Infrared detection quantitated each band on an individual pixel basis using western analysis tools in the Image Studio program.

\section{Gene expression determination}

For most experiments, RNA was isolated using the Qiagen RNAeasy kit following the manufacturer's instructions. As with harvesting cell lysates, when RNA was isolated from synchronized cells for mitosis, the cells were harvested only once the control cells were visually rounding up for mitosis (approximately $8 \mathrm{~h}$ following release from G1/S). cDNA was generated using a Reverse Transcription kit from Applied Biosystems (4368814). Probes for RNA quantification were acquired from Life Technologies with the Taqman gene expression system (Life Technologies). Target gene expression was normalized to a ubiquitous control $(G A P D H)$ utilizing a dual label system. $\mathrm{Cp}$ values were measured using a Light Cycler 480 (Roche). The following probes were used: (AURKB) HS009645858 M1, (CDC20) HS00426680 M1, (UBP1, which encodes LBP1A) HS00232691 M1m, (TFCP2, which encodes LSF) HS00232185 M1, (MAD2L1) HS00365651 M1, and (GAPDH) 4333764F.

\section{Cell viability and cell counting}

Cells were counted on the ViCell XR coulter counter from Beckman Coulter. The ViCell also assayed viability by measuring Trypan Blue permeability. Fifty individual fields per sample were assayed to determine total cell and total viable cell populations.

\section{Cellular senescence measurement}

HeLa cells were synchronized with a double thymidine block with either FQI1 treatment or LSF knockdown. The cells were stained for $\beta$-galactosidase using the activity kit (Kit 9860S) from Cell Signaling Technologies according to the manufacturer's protocol. Following the overnight incubation, cells were imaged on a phase Axiovert $40 \mathrm{CFL}$ (Zeiss) microscope. The number of blue-staining cells was quantified, irrespective of the intensity of the signal, in comparison to the number of cells lacking blue staining.

\section{Statistical analysis}

Statistical significance was determined using a two-tailed Student $\mathrm{T}$ Test (paired tests unless otherwise stated); ${ }^{*} P<0.05,{ }^{* *} P<0.01,{ }^{* * *} P<0.001,{ }^{* * * * *} P<0.0001$ using Prism GraphPad. Pearson correlation coefficient was determined using Excel.

\section{Results \\ Chemical inhibition of LSF induces a delay in mitotic progression with condensed but unaligned chromosomes} In asynchronous populations of hepatocellular carcinoma cells, the LSF small molecule inhibitors (FQIs) resulted in cells delayed with G2/M ("4n") DNA content [16]. In order to characterize this cell cycle-related phenotype in detail, we utilized HeLa cells, which are similarly sensitive to FQI1 treatment and readily able to be synchronized for in depth cell cycle analysis. First, the dose- and timedependence of this phenotype was examined, using cellular DNA content as a readout. Cells were synchronized at G1/S with a double thymidine block (Fig. 1a) and analyzed for cellular DNA content throughout the subsequent cell cycle. Upon release from the G1/S block, the population of vehicle-treated cells proceeded synchronously through $S$ phase, with DNA content in between $2 \mathrm{n}$ and $4 \mathrm{n}$ levels (Fig. 1b, $4.5 \mathrm{~h}$; see Additional file 2 for alignments of each individual peak distribution). The control cells then proceeded to mitosis and largely re-entered G1 again at $8.5 \mathrm{~h}$ in the experiment shown. At 0.9 and $1.8 \mu \mathrm{M}$, FQI1-treated cells were initially delayed in returning from G2/M to G1, remaining with 4n DNA content (Fig. 1b, 8.5 h; Additional file 2), an observation consistent with previous studies [16]. Following this delay, a mix of phenotypic outcomes was observed at $16 \mathrm{~h}$ after release from G1/S, with FQI1treated cells having divided to a 2n DNA content, initiated cell death pathways (subG1 DNA content), or retained their duplicated DNA content. At the highest FQI1 concentration tested $(3.6 \mu \mathrm{M})$, progression of cells away from $2 \mathrm{n}$ content appeared less complete (note skewing of the peak to a lower shoulder even at $8.5 \mathrm{~h}$ ), and never fully reached 4n DNA content. Subsequently, a large fraction of the population converted to subG1 DNA content by $16 \mathrm{~h}$ 

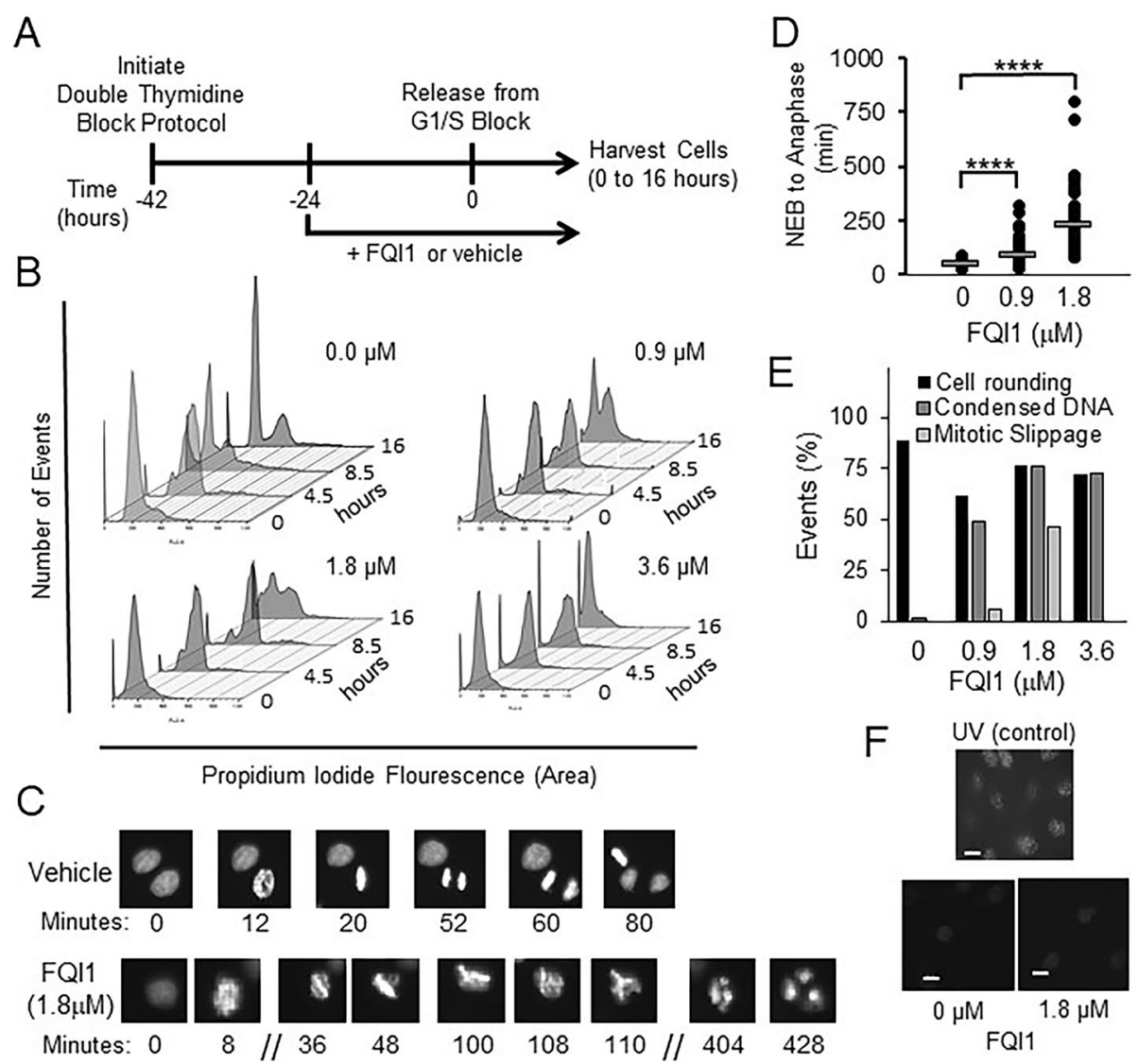

Fig. $1 \mathrm{FQ} 1$-treated HeLa cells exhibit mitotic defects. a Schematic of experimental protocol. Cells released from the double thymidine block in the presence of $20 \mu \mathrm{M}$ of thymidine, plus FQI1 or vehicle, were harvested at multiple times during progression through the cell cycle. $\mathbf{b}$ At the indicated time points following release from the G1/S block with $0,0.9,1.8$, or $3.6 \mu \mathrm{M}$ of FQI1, cells were analyzed for DNA profiling by flow cytometry. Data are representative of at least three independent experiments. Separated, individual flow cytometry images are displayed in Additional file 2. c Representative time-lapse images of individual cells treated with vehicle or 1.8 $\mathrm{MM} \mathrm{FQI1.} \mathrm{Numbers} \mathrm{represent} \mathrm{time} \mathrm{for} \mathrm{one}$ particular cell in the image from nuclear envelope breakdown (designated as time $=0$ for that cell). $\mathbf{d}$ Quantitation of mitotic time from nuclear envelop breakdown (NEB) to anaphase for the population of asynchronous cells during treatment for approximately $16 \mathrm{~h}$ with FQI1 or vehicle. Mitotic times (mean time in minutes $+/$ - standard error of the mean, $n$ ) for vehicle, and 0.9 or $1.8 \mu \mathrm{M}$ FQI1 treatments were: $48.7+/-1.5,104$; $84.5+/-4.9,104$; and $228+/-15,77$; respectively. Mitotic time for cells treated with $3.6 \mu \mathrm{M}$ was not quantifiable, as those cells that entered mitosis at various points during the imaging period never reached anaphase or nuclear division by the end of the 16-h period. e Quantitation of cellular events at increasing concentrations of FQI1 during time lapse microscopy, including percentage of cells that visually rounded up as expected for mitotic entry (by phase contrast), but were delayed with condensed, but unaligned chromosomes, and the percentage that apparently underwent mitotic slippage with formation of multiple (> 2) nuclei. 120-140 cells were analyzed for each condition. $\mathbf{f}$ Bottom: $\gamma$-H2AX staining of HeLa cells treated with vehicle or $1.8 \mu \mathrm{M}$ FQI1. Top: Representative image of UV-treated HeLa cells as a positive control. All images were taken at the same intensity and are representative of two independent experiments. Scale bars: $20 \mu \mathrm{m}$

post release from the G1/S block (Fig. 1b; Additional file 2).

Given limitations in interpretation of population-wide data, it was critical to analyze the phenotype(s) on a per cell basis upon inhibition of LSF. Using HeLa cells stably expressing fluorescently labeled histone H2B, chromosomal DNA was visualized by time-lapse microscopy as each cell passed through mitosis. Asynchronous H2BYFP-expressing cells were treated with increasing concentrations of FQI1 and imaged immediately thereafter. At $1.8 \mu \mathrm{M}$ (Fig. 1c) mitotic progression was delayed with condensed, unaligned chromosomes. Cells subsequently appeared to exit mitosis without proper chromosome segregation, resulting in a multinuclear $(4 n)$ G1 state (Fig. 1c) [16]. In contrast, cells treated with vehicle progressed through mitosis normally (Fig. 1c and d). Mitotic time (time from nuclear envelope breakdown (NEB) to anaphase) was dose-dependent, increasing with increasing concentrations of FQI1 (Fig. 1d). At the lower concentrations of FQI1, cells exited mitosis aberrantly after the mitotic delay (Fig. 1c, d and e). However for cells treated with $3.6 \mu \mathrm{M}$ FQI1, mitotic time for those cells that entered mitosis could not be determined using this experimental design (Fig. 1e). Cells would arrest with 
condensed but unaligned chromosomes but never exited mitosis during the course of the time lapse experiment, either normally or aberrantly, whether entering mitosis at the beginning or end of the experimental window of $11 \mathrm{~h}$ (Addition File 3, Fig. S1A).

In some cell lines, LSF is necessary for upregulation of thymidylate synthase expression and therefore efficient transition through S phase [24]. Since S phase defects can ultimately lead to mitotic defects, DNA damage was monitored by measuring phosphorylated H2AX ( $\gamma$ H2AX) chromosomal foci. Cells treated with $1.8 \mu \mathrm{M}$ FQI1 or vehicle during synchronization were analyzed for $\gamma-\mathrm{H} 2 \mathrm{AX}$ by immunofluorescence $8 \mathrm{~h}$ after release from the G1/S block (Fig. 1f). UV-irradiated cells, a positive control, demonstrated extensive $\gamma$-H2AX staining. In contrast, only comparable, low levels of phosphorylated $\mathrm{H} 2 \mathrm{AX}$ were visualized in both the vehicle- and FQI1-treated cells, consistent with low levels of DNA damage known to occur in cancer cells [25]. This was consistent with our previous studies suggesting that adequate thymidylate synthase expression in tumor cells was likely achieved even with reduction in LSF activity $[15,26]$.

Overall, upon treatment of cells with FQI1, we observed defects in chromosome alignment and segregation, resulting in mitotic delay and multi-nucleation. The lack of elevated DNA damage signals supports the hypothesis that FQI1-mediated mitotic defects are due to a direct requirement for LSF in regulating proper progression through mitosis, and in particular in progressing to metaphase, in which the condensed chromosomes are fully aligned.

\section{LSF small molecule inhibition during cell synchronization reduced expression of mitotic regulators}

The lack of chromosomal alignment is not a phenotype expected to be caused by upregulation of cyclin B expression, which was previously suggested from experiments in asynchronous cells to be a major cause of the FQI1-mediated mitotic delay [16]. Thus, we investigated the effects of FQI1 treatment on the expression of a number of mitotic regulators, using synchronized cells to more carefully assay cell cycle expression. HeLa cells were again synchronized with a double thymidine block (Fig. 2a). Cell populations treated in this manner pass through the subsequent cell cycle in a wave that is generally, although not precisely, synchronous. Only a short window of time is spent in mitosis, on average $50 \mathrm{~min}$ for these HeLa cells (Fig. 1d). Initial analyses when harvesting for flow cytometry for DNA content indicated that around $8.5 \mathrm{~h}$ the cells had just returned to G1 phase, since some were still in mitosis (4n DNA content, Fig. 1b; Additional file 2). By fluorescence microscopy, a range of mitotic figures were observed in separate experiments harvested either at 8 or 8.5 h (Additional File 3, Fig. S1B).
Therefore, for subsequent analyses of RNA or protein levels in mitotic cells, cells were monitored visually starting just prior to $8 \mathrm{~h}$, and harvested only once the control population was observed to significantly round up on the dish, indicating mitotic entry. RNA levels were measured initially in vehicle-treated cells at the G1/S border $(0 \mathrm{~h})$ and in mitosis (approximately $8 \mathrm{~h}$ ). Results are shown for the mitotic regulators Aurora kinase B (AURKB) and Cyclin Division Cycle 20 (CDC20) [27, 28], as expression levels of these genes were altered by FQI1 (see below). In the untreated, control cells, mitotic expression of $C D C 20$ was elevated approximately 6-fold compared to RNA levels at G1/S (Additional File 3, Fig. S1C), as expected. However, AURKB RNA levels in vehicle-treated cells increased only 1.2 fold in mitosis, consistent with dysregulated expression in these cancer cells. Incubation with $1.8 \mu \mathrm{M}$ FQI1 during the synchronization protocol resulted in reduction of both $A U R K B$ and $C D C 20$ RNA levels compared to the control cells $8 \mathrm{~h}$ post release (Fig. 2b). For analysis of protein levels, cells were also harvested in mitosis (around $8 \mathrm{~h}$ ), and levels were quantified after immunoblotting using the LI-COR Odyssey instrumentation, which provides direct measurements of fluorescence levels over a 4-log intensity range. In Fig. 2c and $\mathrm{d}$ are shown both snapshots of the immunoblot images and the independent, direct quantitative measurements, respectively. Consistent with transcript reduction, AURKB and CDC20 protein levels were also reduced in a dose-dependent manner at the time control cells were visually entering mitosis (Fig. 2c and d), whereas LSF protein levels were unchanged, as expected (Fig. 2c). The impact of the downregulation of AURKB was tested by monitoring phosphorylation of an AURKB substrate. Phosphorylation of Histone 3 on Serine 10 [29] was reduced by FQI1 in a dose-dependent manner (Fig. 2c and d).

In stark contrast to the previous results in asynchronous cells [16], in the synchronized cells treated with up to $1.8 \mu \mathrm{M}$ FQI1, Cyclin B protein levels were similar to those in control cells, and certainly not increased (Fig. 2c), despite obvious delays in mitotic progression at such concentrations (Fig. 1b-d). At the higher concentrations of FQI1 during the synchronization procedure, Cyclin B levels were actually downregulated (Fig. 2c). In order to investigate downregulation of cyclin B further, we analyzed levels of Cyclin B in synchronized cells with vehicle versus a high concentration of FQI1 $(5 \mu \mathrm{M})$ when treated only following, rather than during, the synchronization process (Additional File 3, Fig. S1D). In this case, Cyclin B levels peaked around mitotic entry at similar levels in both control and FQI1-treated cells. In control cells, Cyclin B levels declined as cells continued through the cell cycle, as expected, but Cyclin B remained elevated in the FQI1-treated cells, which 

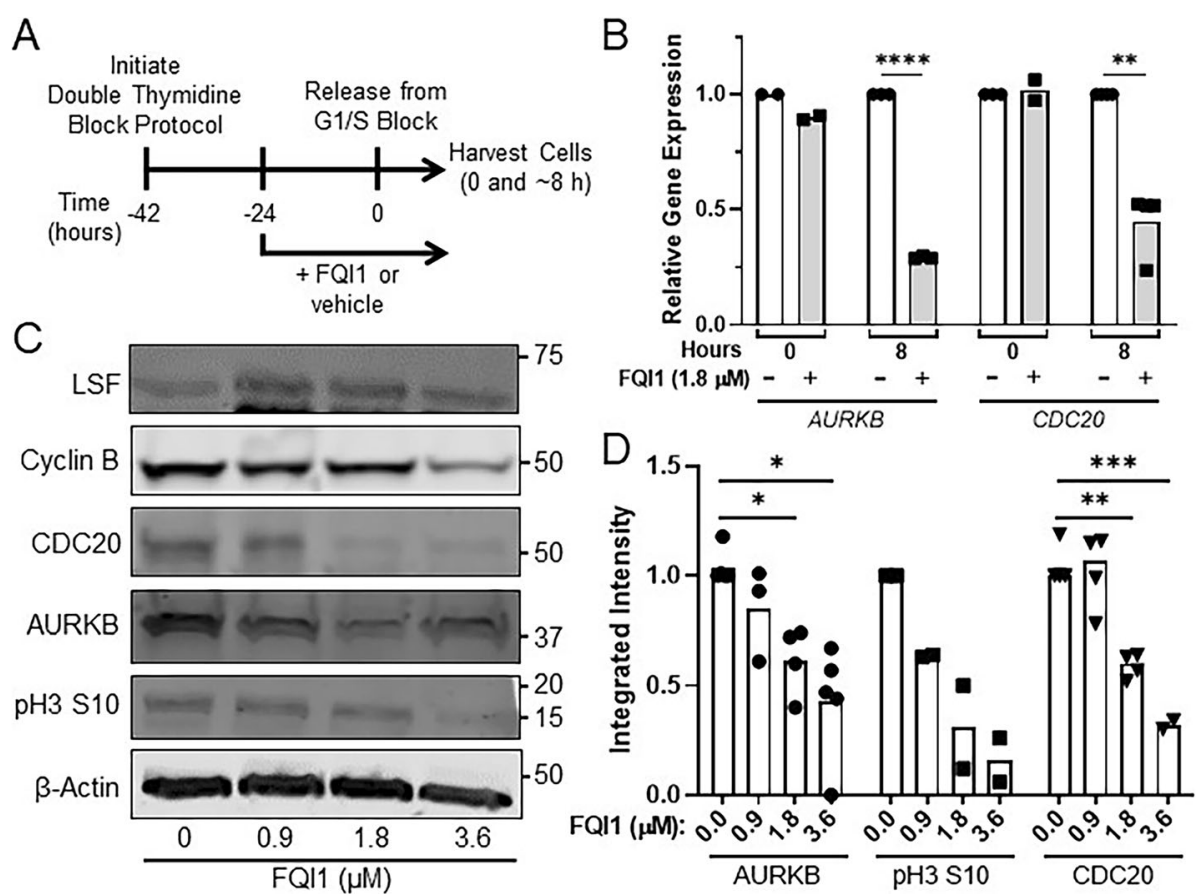

Fig. 2 FQI1 treatment diminished expression of mitotic regulators. a Schematic of experimental protocol. FQl1 or vehicle was added to HeLa cells during synchronization to the G1/S border using a double thymidine block. Cells were released from the block, including addition of $20 \mu \mathrm{M}$ of thymidine, for subsequent analyses. $\mathbf{b}$ Lysates from cells treated with vehicle or $1.8 \mu \mathrm{M}$ FQ11 were harvested at release from the G1/S block (0 h) or when control cells visually reached mitosis ( $\sim \mathrm{h}$ post release) and analyzed for AURKB or CDC20 RNA levels, as normalized to levels of GAPDH RNA. Data points and means are plotted relative to the expression from vehicle treated cells at each time point and are derived from 2 to 4 independent experiments. ${ }^{* *} p=0.0045 ;{ }^{* * *} p<0.0001$. c Representative immunoblots for the indicated proteins in cell lysates harvested when control cells visually reached mitosis ( $~ 8 \mathrm{~h}$ post release from a G1/S block), after treatment with increasing concentrations of FQI1 from 0 to 3.6 $\mathrm{MM}$. Molecular weight markers are indicated on the right side. Relative intensities can only be compared within each separate immunoblot of each protein showing levels at increasing FQI1 concentrations, not between separate immunoblots. The images were cropped to indicate the proteins of interest; full images are in Additional file 4. $\mathbf{d}$ Independent quantitation of the protein levels from cell lysates harvested for mitotic expression (as in panel $\mathbf{c}$ ). Individual protein levels were normalized to those of $\beta$-actin from the same lysate. Data points and means are from 2 to 5 independent experiments. ${ }^{*} p=0.037(\mathrm{FQI} 1=1.8 \mu \mathrm{M}), 0.015(\mathrm{FQ} \mid 1=3.6 \mu \mathrm{M}) ;{ }^{* *} p=0.0048 ;{ }^{* *} p=0.0005$ (unpaired T test)

remained arrested in mitosis during this protocol [16]. First, these findings demonstrate that elevated levels of cyclin B observed in asynchronous cell populations are the result, not the cause of the mitotic arrest induced by FQI1, unlike what was previously suggested [16]. Furthermore, these results suggest that the decrease in Cyclin B levels when $3.6 \mu \mathrm{M}$ FQI1 is present during cell synchronization (Fig. 2c) must result from FQI1 effects during previous cell cycles. In particular, because cyclin $\mathrm{B}$ is required for mitotic entry, lower levels of cyclin B suggested that cells treated with higher concentrations of FQI1 during synchronization were not efficiently proceeding into the final mitosis after release from the G1/S block (see also below). This is consistent with the bulk cellular DNA profiling curves (Fig. 1b; Additional file 2), since this analysis cannot distinguish between " $2 \mathrm{n}$ " as early G1 versus G1/S or " $4 n$ " as G2 versus M. This complicates straightforward interpretation of the bulk expression results, with ambiguity as to whether decreased levels of AURKB and/or CDC20 were the cause of the mitotic cell cycle defects, or also the consequence of cell cycle defects resulting from lower LSF activity during the first passage through mitosis in the synchronization procedure.

For a stringent examination of whether diminished $A U R K B$ and $C D C 20$ gene expression resulted from lack of cell cycle progression of LSF inhibited cells or from diminished expression of these genes in mitosis in the presence of FQI1, we analyzed RNA in synchronized, LSF-inhibited cells only from cells demonstrably in mitosis, isolated by standard mitotic shakeoff methodology. A reproducible decrease in $C D C 20$ (Additional File 3, Fig S2B), but not AURKB (Additional File 3, Fig. S2A), RNA was observed in this experiment. We also sought to identify candidate LSF target genes by identifying binding sites for LSF near the genes. Given the lack of a sufficiently robust antibody against LSF for chromatin immunoprecipitation (ChIP), a stable HEK cell line inducibly expressing HA-tagged LSF [15] was used for the ChIP-sequencing analysis. Gene ontology analysis of 
genes whose transcription initiation sites were located within $20 \mathrm{~kb}$ of the ChIP peaks only revealed a small number of statistically significant functional or pathway categories, with a focus on categories involving nucleosomes, chromatin, transcriptional regulation, and splicing regulation (Additional File 3, Table S1), none of which seemed particularly revealing with regards to the phenotypes observed here. Multiple HA-LSF binding peaks were observed around the $A U R K B$ gene (Additional File 3, Fig. S2C), and binding of LSF was validated both at the AURKB promoter and around $3000 \mathrm{bp}$ upstream of the transcription start site by quantitative PCR (Additional File 3, Fig. S2D). In contrast, no HA-LSF binding peaks were observed within $20 \mathrm{~kb}$ of the $C D C 20$ gene. Taken in combination, whether LSF activates $A U R K B$ expression in these, or other, cells remains unresolved. The mitotic shakeoff experiment does suggest that LSF regulates $C D C 20$ expression, either from distant binding sites, or indirectly. Global gene expression data from cells treated with FQI1 only between G1/S and mitosis did not identify dysregulation of RNA encoding any other mitotic regulators [30].

Despite not pinpointing mitotic genes directly transcriptionally regulated by LSF, these results did provide molecular biomarkers in this synchronized cell system for responsiveness to the LSF inhibitor FQI1.

RNAi mediated knockdown of LSF phenocopies inhibition of LSF with the small molecule inhibitor FQI1

Specificity of small molecule inhibitors to their intended target is a key requirement so that biological consequences of inhibitor effects can be mechanistically attributed to the target of interest. Knowledge of specificity is of even more importance in developing such inhibitors for use in the clinics. FQI1 inhibits LSF DNA-binding and protein-binding activities, whereas it does not impact activity of a number of other transcription factors, both with disparate and similar structural domains $[15,31]$. However, in order to demonstrate that the overall cellular consequences of FQI1 treatment were specific consequences due to inhibiting LSF, a direct comparison with specific removal of LSF was required. Although LSF has a long half-life, of approximately $24 \mathrm{~h}$ [32], we identified an siRNA that resulted in robust and durable knockdown of LSF RNA and protein, at least for 48-96 h (Fig. 3b-d, Additional File 3, Fig. S3A-B). In addition, since certain siRNAs can cause nonspecific reduction in mRNA encoding MAD2 [33], which controls the spindle assembly checkpoint and therefore the rate of progression through mitosis, we verified that the selected siRNA targeting LSF did not inadvertently reduce MAD2L1 RNA levels (Additional File 3, Fig. S3C).

In order to compare downstream biomarkers from FQI1 and LSF siRNA treatments, $A U R K B$ or $C D C 20$
RNA levels were measured following RNAi mediated knockdown of either LSF or a non-expressed control. Cells were transfected with siRNAs, to initiate protein knockdown, $30 \mathrm{~h}$ prior to synchronization. RNA and protein expression were analyzed at two time points when control cells were arrested at G1/S $(0 \mathrm{~h})$ following the synchronization protocol and when these cells were largely in mitosis after release from the block (approximately $8 \mathrm{~h}$ ) (Fig. 3a, Additional File 3, Fig. S4A, Additional file 2). For ease of comparison, RNA levels were plotted relative to the level in the control siRNA sample at each time point. At $20 \mathrm{nM}$ siRNA, significant knockdown of LSF-encoding RNA (TFCP2, Fig. 3c) was achieved over this time course. LSF protein levels were also decreased significantly at all three concentrations of LSF siRNA, but to the greatest degree with $20 \mathrm{nM}$ LSF siRNA (top immunoblot, Fig. 3d). Consistent with the results generated with the LSF small molecule inhibitor at $8 \mathrm{~h}$ after $\mathrm{G} 1 / \mathrm{S}$ release (Fig. 2b), AURKB and CDC2O RNA levels were significantly reduced upon knockdown of LSF (Fig. 3c). Immunoblotting of lysates harvested at the time of mitotic entry of the control cells (approximately $8 \mathrm{~h}$ ) confirmed a dose-dependent reduction in AURKB and CDC20 protein levels after siRNA-mediated knockdown of LSF (Fig. 3d and e), consistent with the findings upon inhibition of LSF with FQI1 (Fig. 2c and d). As expected, phosphorylation of AURKB substrate Serine 10 of histone H3 [29, 34] was reduced (Fig. 3d). Finally, as with FQI1 treatments, Cyclin B levels were also reduced in a dose-dependent manner. With LSF siRNA treatment, all mitotic protein levels were decreased even at the lowest amount of the siRNA, including that of cyclin B, reflective of the DNA profiling data in which a significant fraction of cells never proceeded from 2n DNA content after release from the G1/S block, unlike with the control siRNA (Additional File 3, Fig. S4A; Additional file 2). This effect was similar, although more pronounced, than that observed in experiments using FQI1. Overall, LSF siRNA phenocopied the molecular consequences of FQI1 on protein expression, whether due to direct transcriptional effects, and/or consequences of cell cycle dysregulation.

To determine whether LSF knockdown resulted in similar mitotic phenotypes to those observed with FQI1, synchronized YFP-H2B-expressing HeLa cells were transfected with siRNAs targeting LSF or a nonexpressed control. A single thymidine block protocol was sufficient for synchronization (Fig. 4a), as mitotic progression is viewed on a cell-by-cell basis. This protocol results in a partial cell cycle synchronization, with $84 \%$ of the control cells rounding up and undergoing mitosis in a smaller window of time following release from the block (Fig. 4d; Additional file 1; Additional File 3, Fig. S4B). Surprisingly a larger 


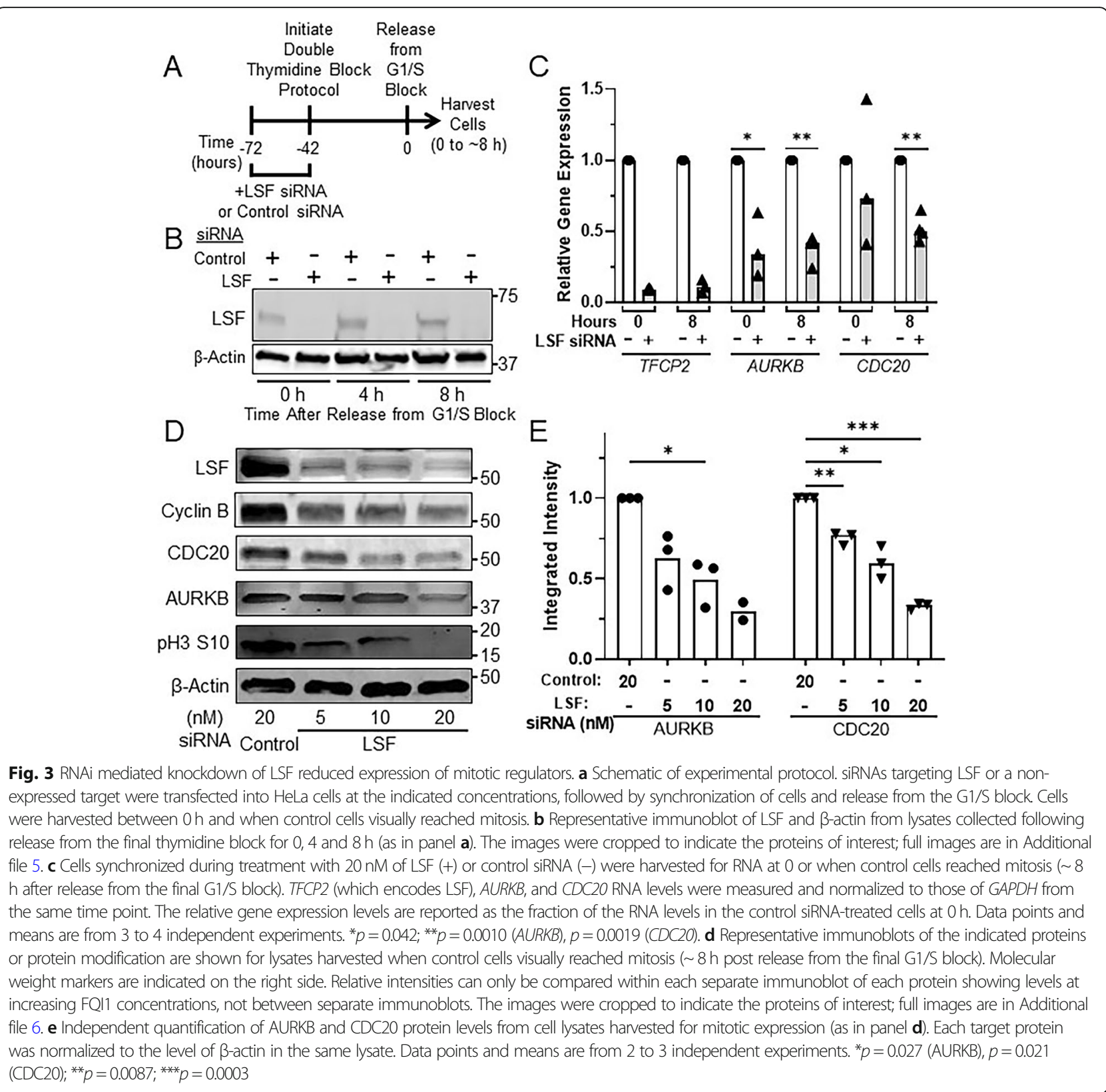

fraction of the LSF siRNA-treated cells visually rounded up than underwent DNA condensation subsequent to release from the G1/S block (Fig. 4d). Representative time-lapse images of cells treated with the highest concentration $(20 \mathrm{nM})$ of either LSF targeting siRNA or control siRNA highlight dramatic changes in mitotic progression. Control cells exhibited progression through normal mitotic phases within an hour, as expected (Fig. 4b and c). However, cells with diminished LSF levels exhibited an extensive delay with condensed chromosomes that never achieved stable alignment, generally followed by defective cellular division and multinucleation
(Fig. 4b). In addition, some cells remained in mitosis with condensed chromosomes throughout the entire time lapse analysis. Quantitation documented that mitotic time was dramatically increased when LSF levels were reduced (Fig. 4c). We note that 5 and $10 \mathrm{nM}$ of LSF siRNA resulted in slightly longer times for mitotic progression than did 20 $\mathrm{nM}$, which is likely due to the inability of a number of cells at the $20 \mathrm{nM}$ LSF siRNA treatment (the most perturbed cells) to fully progress through mitosis. When siRNA-transfected cells were imaged by time lapse microscopy after a thymidine block, there was an inverse correlation between higher levels of LSF knockdown and 


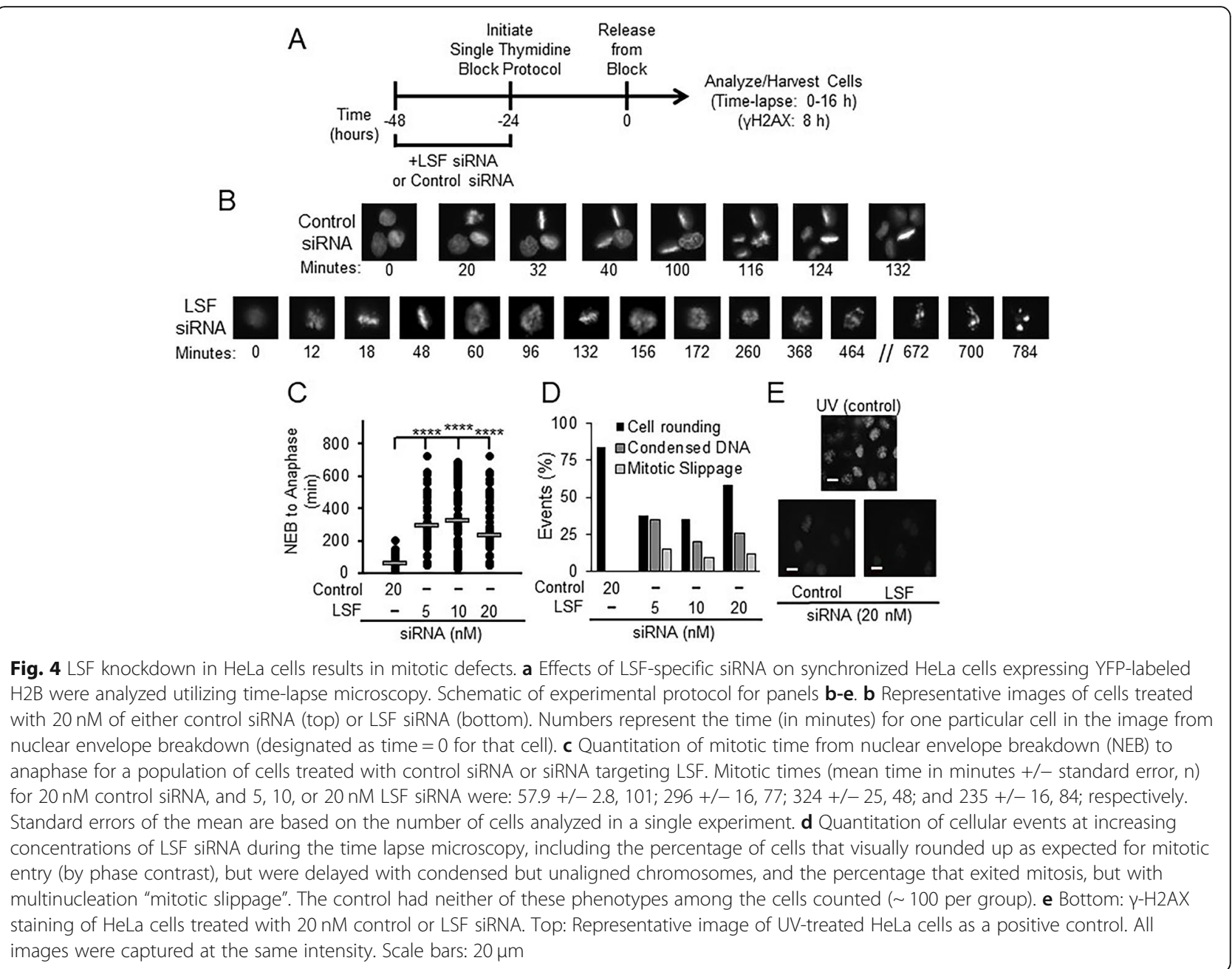

the number of cells undergoing nuclear envelop breakdown (Additional File 3, Fig. S4B).

By histone $\mathrm{H} 2 \mathrm{~B}$ fluorescence from the time lapse data, the most striking mitotic outcome for individual cells treated with LSF siRNA after the extended delay in mitosis appeared to be mitotic slippage (Fig. 4b). The mitotic slippage outcomes were confirmed by immunofluorescence of synchronized cell populations, co-stained for DNA and $\alpha$-tubulin (Additional File 3, Figs. S5A-B). Quantitation of these immunofluorescence data demonstrated significant increases in cells with condensed, but nonaligned chromosomes, incomplete cytokinesis, and multinucleation upon LSF knockdown. These phenotypes mimicked those observed with FQI1 treatment using a parallel treatment and synchronization protocol, and therefore analyzed at $40 \mathrm{~h}$ after FQI1 treatment was initiated (Additional File 3, Fig. S5C-D). Using this synchronization protocol with FQI1, outcomes from mitotic slippage reflecting the eventual degradation of cyclin B during mitotic arrest could be assessed, unlike in the time-lapse experiment in which the maximum time of exposure to FQI1 was $11 \mathrm{~h}$. Finally, treatments with both FQI1 and LSF siRNA yielded mitotic cells with cellular protrusions (Additional File 3, Fig. S5E).

Also consistent with the results from FQI1 treatment, knockdown of LSF did not induce phosphorylated $\mathrm{H} 2 \mathrm{AX}(\gamma-\mathrm{H} 2 \mathrm{AX})$ foci, as monitored the beginning of mitosis in a synchronized cell population (Fig. 4e). This result suggests that the effects of inhibiting LSF on mitotic progression are not due to defects induced indirectly in $\mathrm{S}$ phase.

LSF has a widely expressed paralog, LBP1A [35], whose activity is also inhibited by FQI1 (T. Grant, unpublished observations). Unlike LSF, however, LBP1A has not yet been implicated in cancer [1, 2], which is consistent with our results that knockdown of LSF alone caused the same molecular and phenotypic outcomes as those caused by FQI1. Nonetheless, to determine the potential contribution of LBP1A to FQI1 outcomes, we investigated the mitotic phenotypes upon LBP1A siRNA 
treatment. An identified siRNA resulted in robust and durable knockdown of LBP1A-encoding RNA (Additional File 3, Fig. S6A), with no reduction in MAD2L1 RNA levels (Additional File 3, Fig. S6B). Using two distinct assays, knockdown of LBP1A did reduce overall cell proliferation in the cell population to a limited extent, but much less so than did knockdown of LSF (Fig. 5a-b). Despite this slight decrease in cell number over time relative to the control, LBP1A knockdown did not lead to any significant drop in cell viability between 72 and $96 \mathrm{~h}$ post-transfection, unlike the dramatic drop in viability evident upon LSF knockdown at this time interval (Fig. 5b). Furthermore, LBP1A knockdown did not observably inhibit mitotic progression as measured by cellular DNA profiling (Additional File 3, Fig. S6C). As a more sensitive assay, time-lapse microscopy did detect a subtle increase in average mitotic time upon LBP1A knockdown (1.5-fold, Fig. 5c-d), but with only a small percentage of the cells being demonstrably affected. This limited extent of mitotic delay is consistent with the overall limited reduction in cell proliferation upon LBP1A knockdown. Notably, no abnormal mitotic phenotypes were observed either by time-lapse or immunofluorescent microscopy, however. Given the minimal cellular consequences upon inhibiting LBP1A, we conclude that inhibition of LSF activity is what drives the dramatic FQI1-mediated mitotic defects.

\section{Induction of cellular senescence following inhibition of LSF}

In addition to mitotic delay resulting from LSF inhibition, some cells undergoing synchronization while inhibiting LSF were arrested at other points in the cell cycle, as suggested above by the reduction in cyclin B expression. Cellular DNA profiling of both $3.6 \mu \mathrm{M}$ FQI1-treated and LSF siRNA-treated cells being synchronized with a double thymidine block captured cells that no longer progressed from the $2 \mathrm{n}$ state through $\mathrm{S}$ phase upon release from the G1/S block (Fig. 1b, Additional File 3, Fig. S4A; Additional file 2), and time-lapse microscopy showed that a
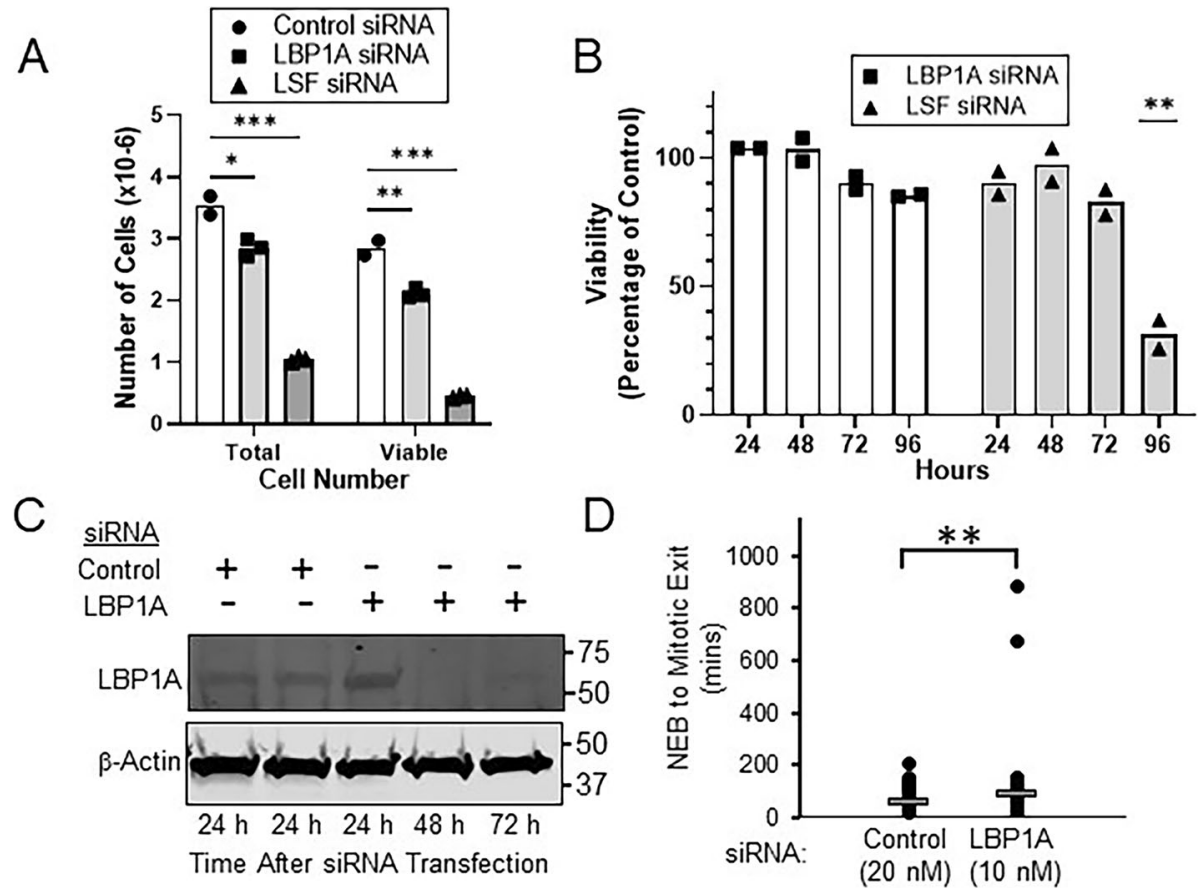

Fig. 5 LBP1A knockdown in HeLa cells results in limited growth reduction, and minimal mitotic delay with no apparent mitotic defects. a-b Asynchronous HeLa cells were transfected with $20 \mathrm{nM}$ of control siRNA or siRNAs targeting either LSF or LBP1A. a Total cell number was measured simultaneously with viability at $120 \mathrm{~h}$ post transfection. Data points are technical replicates and means from a single experiment; results are representative of three independent experiments. $\mathbf{b}$ Cells were analyzed at the indicated times for viability by the Promega MTT assay. The data are represented as the percentage of viability, compared to that of the control siRNA. Data points and means are derived from 2 independent experiments. ${ }^{* *} p=0.0064$ (LSF vs. control siRNA, unpaired T test). $\mathbf{c}$ HeLa cells transfected with $20 \mathrm{nM}$ LBP1A or control siRNAs were harvested at the indicated times during the cell synchronization protocol using a double thymidine block (see Fig. 3a). Representative immunoblots of LBP1A and $\beta$-actin are shown. The images were cropped to indicate the proteins of interest; full images are in Additional file 5. d H2B-YFP-labeled HeLa cells were synchronized with a single thymidine block following transfection with a siRNA targeting either LBP1A or a non-expressed gene as a control. Cells were imaged using time lapse microscopy. Mitotic time was determined by measuring time from nuclear envelope breakdown (NEB) to anaphase. Mitotic times (mean time in minutes $+/-$ standard error, $\mathrm{n}$ ) for $20 \mathrm{nM}$ control siRNA and $10 \mathrm{nM}$ LBP1A siRNA were: $57.9+/-2.8,101$; and $86.6+/-10.6,100$; respectively. ${ }^{* *} p=0.009$ 
considerable fraction of the cells treated with LSF siRNA during a thymidine block never underwent nuclear envelope breakdown during 10-12 $\mathrm{h}$ after release from the G1/S block (Additional File 3, Fig. S4B). Mitotic defects, caused by multiple distinct insults, can lead to senescence after G1 re-entry with either $2 \mathrm{n}$ or 4n DNA content $[36,37]$. Thus, we hypothesized that mitotic defects from decreasing LSF levels or activity during previous cell divisions resulted in senescence. To test this hypothesis, cells were synchronized as before by a double thymidine block in the presence of FQI1, or LSF siRNA, and analyzed for senescence by monitoring $\beta$-galactosidase activity at low $\mathrm{pH}$ [38] at a time point when control cells entered mitosis. Both reduction in LSF levels and inhibition of LSF activity resulted in significantly greater numbers of $\beta$ galactosidase-positive cells (stained blue) compared to the respective controls (Fig. 6a-b). Although the absolute degree of senescence varied between experiments, and was generally more pronounced with LSF siRNA treatment, overall there was a consistent 3- to 5-fold increase in senescent cells with increasing amounts of LSF inhibition. Only treatment with $0.9 \mu \mathrm{M}$ FQI1 was not sufficient to induce senescence (Fig. 6c-d). These data show that inhibition of LSF can result in senescence of cancer cells, and support the hypothesis that reduced LSF levels or activity during previous cell cycle(s) can predispose cells to senescence.

\section{Discussion}

LSF is an oncogene in multiple cancer types, notably including hepatocellular carcinoma $[1,2,20]$. Small molecule inhibitors directly targeting LSF inhibited hepatocellular carcinoma cell proliferation in vitro and tumor growth in vivo with no signs of toxicity at doses required for tumor inhibition [15-17]. Together, these data suggested that LSF is a promising therapeutic candidate for hepatocellular carcinoma patients, and likely for other cancer types. In order to confirm the key characteristic that anti-tumor effects of FQIs were consistent with specific targeting of LSF, we demonstrated here that a siRNA targeting LSF produced strikingly similar phenotypes to that of FQI1 treatment in multiple aspects. Furthermore, knockdown of the close LSF paralog, LBP1A, did not result in such mitotic defects. Thus, we conclude that LSF is the FQI1 target that is required for accurate and efficient mitotic progression in these cancer cells.

The primary consequence of immediate inhibition by the LSF inhibitor FQI1 (Fig. 1c-e), or the longer term LSF inhibition required for sufficient LSF knockdown (Fig. 4b-d) was the delay in progression through mitosis with condensed, but unaligned chromosomes. This can lead to multiple cellular outcomes. First, if unable to progress through normal metaphase alignment, mitotic slippage yields multinucleated cells, which lead to apoptosis, shown previously in hepatocellular carcinoma cell lines $[15,16]$, and here in HeLa cells as sub-G1 cellular DNA content (Fig. 1b, Additional File 3, Fig. S4A;
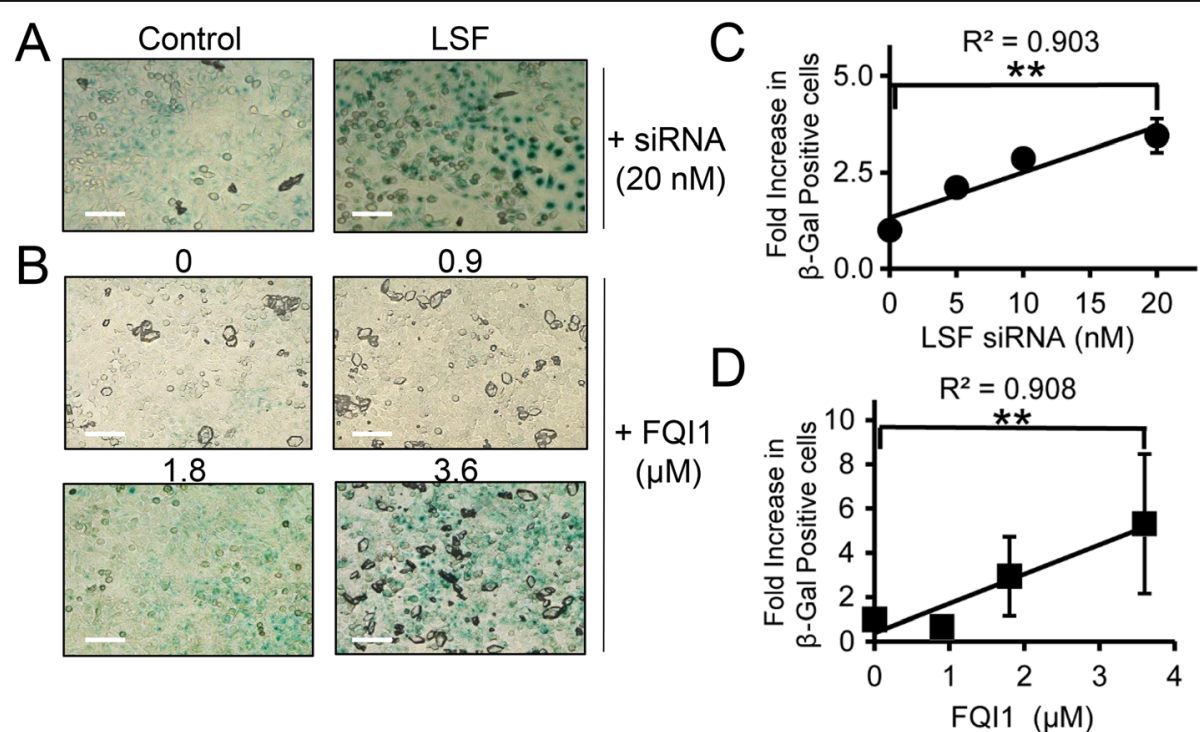

Fig. 6 Inhibition of LSF activity induces cellular senescence. $\mathbf{a}-\mathbf{b}$ HeLa cells treated either with increasing concentrations of FQI1 $(0=$ vehicle control) or with control or LSF siRNA were synchronized using a double thymidine block (protocols in Fig. 2a and 3a, respectively) and then fixed at $8 \mathrm{~h}$ after release from the second thymidine block and stained for $\beta$-galactosidase activity. Phase contrast images were taken at 20x magnification. Images shown are representative of three independent experiments. c-d The correlation of increasing LSF siRNA concentrations (c) or increasing FQI1 concentrations (d) with the number $\beta$-galactosidase positive cells is depicted as a fold change compared to the control for each individual FQI 1 and LSF siRNA concentration. The absolute percentage of senescent cells varied somewhat for both controls and experimental samples, ranging for example from 87 to $98 \%$ at $20 \mathrm{nM} \mathrm{LSF}$ siRNA and $73-96 \%$ at $3.6 \mu \mathrm{M}$ FQ11. The data reflect analysis of 75 cells per condition in each experiment, averaging over three independent experiments. Pearson correlation coefficients are indicated. Scale bars: $50 \mu \mathrm{m}$ 
Additional file 2). Second, less severe mitotic defects that permit cell division can also result in senescence after division, yielding cells with " $2 \mathrm{n}$ " genomic DNA content unable to progress further through the cell cycle. Finally, it is possible that mitotic slippage back into G1 yielding cells with " $4 \mathrm{n}$ " genomic DNA content may also senesce. Here, we demonstrate induction of senescence in a dose-dependent manner by treating with either LSF inhibitor or LSF-targeting siRNA during the synchronization protocol (Fig. 6).

The simplest interpretation for the mitotic defects observed upon LSF inhibition would be that, as a transcription factor, LSF directly regulates expression of mitotic regulators. Both FQI1 and LSF siRNA do result in downregulation of $A U R K B$ and $C D C 20$ expression, initially suggesting that the mitotic phenotypes could be caused by inhibition of Aurora kinase $\mathrm{B}$ and/or $\mathrm{CDC} 20$. Aurora kinase $\mathrm{B}$ inhibition leads to defects in kinetochore-microtubule attachment and cytokinesis, followed by multinucleation [39, 40], and knockdown of CDC20 results in an increase in mitotic time [28]. However, upon deeper analysis, including demonstration of the onset of senescence in a subpopulation of the inhibited cells, it is unclear at this time as to whether lower AURKB and CDC20 levels cause, or rather are the consequence of, disruption of normal cell cycle progression. Nonetheless, their diminished expression provide molecular biomarkers for LSF inhibition in vitro. Importantly, our analysis conclusively demonstrated that alteration of cyclin B levels are unrelated to the FQI1-mediated mitotic phenotype, refuting a previously reported interpretation from experiments using asynchronous populations of hepatocellular carcinoma cells [16]. We propose that the observed, elevated cyclin B protein levels in FQI1treated versus control asynchronous cells resulted simply from accumulation of cells in mitosis when treated with FQI1 for $12-24 \mathrm{~h}$, whereas the control cells continually cycled in the asynchronous populations. Furthermore, the two CDK1/cyclin B inhibitors used in Rajasekaran et al. to attempt to rescue the mitotic defects are not specific to inhibiting CDK1 activity: the translation inhibitor cycloheximide influences many cell cycle processes and Roscovitine also robustly inhibits the cell cycle regulator CDK2, thus complicating the interpretations made. Overall, these complications underscore the need to perform population-level experiments in synchronized cells, as shown here, when dissecting mitotic defects.

Since FQIs are specific for targeting LSF, and both these inhibitors and siRNAs targeting LSF can induce cell death or senescence in cancer cells in vitro, it is worthwhile to consider the targeting strategy for LSF inhibition in patients. Many cancer drug candidates target mitosis in an effort to exploit this key vulnerability of cancer cells. However, many such therapies have failed in trials, which may result from: (1) tumor escape, where pathway redundancy or evasive resistance in mammalian cells enables the tumor cell to escape the therapy [41, 42], or (2) low mitotic index where the drug half-life may not be long enough to suppress the target when cell division is triggered for any particular tumor cell [43, 44]. As a target, LSF may have an advantage toward avoiding tumor escape. Inhibiting a transcription factor can target multiple pathways simultaneously, thus the likelihood that system redundancy would fully compensate is diminished. In addition, the issue of low mitotic index may be avoidable for the LSF inhibitors, since the apparent lack of toxicity in preclinical models may permit dosing in manners that generate sustained drug levels. For these reasons described, it is of interest to evaluate LSF inhibitors as a potential therapeutic strategy in multiple cancer types. Here, we demonstrate antitumor activities of LSF inhibitors in HeLa cells, a cervical cancer cell line from which LSF was initially purified, due to high levels of expression in these cells [45]. Cervical cancer is one of the leading causes of death among women for which treatment options are limited (e.g. surgical, chemotherapy, palliative) [46]. Therefore, further analysis of anti-tumor activity in other preclinical models for cervical cancer are warranted to determine whether or not LSF might generally be a relevant target for treatment of this disease.

Gene silencing-based approaches may also provide a useful strategy to counter low mitotic index for hepatocellular carcinoma patients. The first RNAi drug, which uses a lipid nanoparticle to encapsulate and efficiently deliver siRNA to hepatocytes, was recently approved following robust and durable gene silencing over the 18month pivotal study [47]. Additionally, a ligand-based strategy to deliver LSF siRNA to hepatocytes may provide added benefit as recent human data using a triantennary $\mathrm{N}$-acetylgalactosamine (GalNAc) mediated siRNA delivery system demonstrated robust knockdown of a hepatic target that was sustained for more than a year $[48,49]$. The target of GalNAc, asialoglycoprotein receptor [22], is expressed in early stages and often in later stages of hepatocellular carcinoma [50], although whether tumors retain ubiquitous expression is not clear.

\section{Conclusions}

The specificity of FQI1 for LSF was confirmed by comparing cellular and molecular outcomes of small molecule inhibitors that eliminate LSF activity to those achieved following targeted LSF protein depletion using RNAi technology. Both mechanisms resulted in similar mitotic defects, followed by cellular death or senescence, 
proving that LSF regulates mitosis in cancer cells. Therefore, the anti-tumor activity of FQI1 in multiple preclinical models is most likely due to loss of LSF activity. These findings support the candidacy of LSF targeting agents for treatment of hepatocellular carcinoma, as well as other cancers in which LSF is identified as an oncogene.

\section{Supplementary information}

Supplementary information accompanies this paper at https://doi.org/10 1186/s12885-020-07039-1.

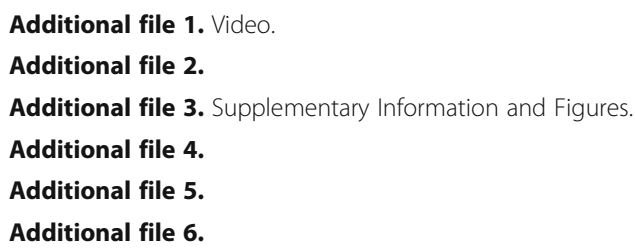

\section{Abbreviations}

AURKB: Aurora kinase B; CDC20: Cyclin Division Cycle 20; ChIP: Chromatin immunoprecipitation; FQIs: Factor Quinolinone Inhibitors; GalNAc: Nacetylgalactosamine; H2B-YFP: YFP-tagged histone H2B protein; NEB: Nuclear envelope breakdown

\section{Acknowledgements}

We thank Nicholas O'Neill for bioinformatics assistance in RNA-seq analysis for cell line validation and Jessica Biagi for assistance with immunoblotting experiments.

\section{Authors' contributions}

JLSW performed and interpreted all the experiments except the time lapse and ChIP experiments, and drafted the manuscript. KG performed the time lapse data acquisition and analysis. MPR generated the fluorescently tagged cells used for the time lapse study. HGC performed the ChIP experiment. PS generated RNA from mitotic shakeoff cells and performed RNA-seq and genomic PCR analysis to validate the HeLa cell line. HS and CSP analyzed the ChIP data. SES provided the LSF small molecule inhibitors and contributed to the analysis of the data. KF substantively revised the manuscript, and provided overall guidance and support. JS contributed to experimental design and interpretation oversight of the time lapse experiments. UH contributed to the conception of the work, overall experimental design, interpretation of results, and substantive revision of the manuscript. All authors approved of the final manuscript.

\section{Authors' information}

Not applicable.

\section{Funding}

The research was supported by: Alnylam Pharmaceuticals, Inc. (JLSW, KF), Boston University (JLSW, UH, SES), BU Undergraduate Research Opportunity (MR), New England Biolabs, Inc. (HGC), and the NIH (R01 GM078240) to SES. These funding sources provided salaries, stipends, and supply funds for the study. None of the funding sources were directly involved in the design of the study, in the collection, analysis, and interpretation of the data, or in the writing of the manuscript. The final manuscript was approved by both Alnylam Pharmaceuticals, Inc. and New England Biolabs, Inc. by standard procedures, with no revisions requested.

\section{Availability of data and materials}

The ChIP-seq datasets generated and analyzed during the current study are available in the GEO repository with the dataset number GSE132419, (https:// www.ncbi.nlm.nih.gov/geo/query/acc.cgi?acc=GSE132419).

\section{Ethics approval and consent to participate} Not applicable.
Consent for publication

Not applicable.

\section{Competing interests}

SES and UH are co-founders of Lamerigen, Inc. JLSW and KF are employed by Alnylam Pharmaceuticals. The remaining authors declare no potential conflict of interest.

\section{Author details}

${ }^{1}$ Alnylam Pharmaceuticals, Inc., Cambridge, MA 02142, USA. ²Department of Biology, Boston University, 5 Cummington Mall, Boston, MA 02215, USA. ${ }^{3}$ Department of Systems Biology, Harvard Medical School, Boston, MA 02115, USA. ${ }^{4}$ MCBB Graduate Program, Boston University, Boston, MA 02215, USA. ${ }^{5}$ New England BioLabs, Ipswich, MA 01938, USA. ${ }^{6}$ Data Science Institute, Takeda Pharmaceuticals International, Inc., Cambridge, MA 02139, USA. ${ }^{7}$ Broad Institute of Massachusetts Institute of Technology and Harvard, Cambridge, MA 02142, USA. ${ }^{8}$ Department of Medical Oncology, Dana-Farber Cancer Institute and Harvard Medical School, Boston, MA 02115, USA.

${ }^{9}$ Center for Molecular Discovery, Department of Chemistry, Boston University, Boston, MA 02215, USA.

Received: 11 February 2020 Accepted: 4 June 2020

Published online: 06 July 2020

\section{References}

1. Kotarba G, Krzywinska E, Grabowska Al, Taracha A, Wilanowski T. TFCP2/ TFCP2L1/UBP1 transcription factors in cancer. Cancer Lett. 2018:420:72-9.

2. Yoo BK, Emdad L, Gredler R, Fuller C, Dumur $\mathrm{Cl}$, Jones $\mathrm{KH}$, et al. Transcription factor late SV40 factor (LSF) functions as an oncogene in hepatocellular carcinoma. Proc Natl Acad Sci U S A. 2010;107:8357-62.

3. Fan R-H, Li J, Wu N, Chen P-S. Late SV40 factor: a key mediator of notch signaling in human hepatocarcinogenesis. World J Gastroenterol. 2011;17: 3420-30.

4. Kim JS, Son SH, Kim MY, Choi D, Jang I-S, Paik SS, et al. Diagnostic and prognostic relevance of $\mathrm{CP} 2 \mathrm{C}$ and $\mathrm{YY} 1$ expression in hepatocellular carcinoma. Oncotarget. 2017:8:24389-400.

5. Zhang X, Sun F, Qiao Y, Zheng W, Liu Y, Chen Y, et al. TFCP2 is required for YAP-dependent transcription to stimulate liver malignancy. Cell Rep. 2017: 21:1227-39.

6. Jiang H, Du J, Jin J, Qi X, Pu Y, Fei B. LSF expression and its prognostic implication in colorectal cancer. Int J Clin Exp Pathol. 2014:7:6024-31.

7. Yuedi D, Yuankun C, Jiaying Z, Han L, Yueqi W, Houbao L, et al. TFCP2 activates beta-catenin/TCF signaling in the progression of pancreatic cancer. Oncotarget. 2017;8:70538-49

8. Laursen L. A preventable cancer. Nature. 2014:516:S2-3.

9. Llovet JM, Villanueva A, Lachenmayer A, Finn RS. Advances in targeted therapies for hepatocellular carcinoma in the genomic era. Nat Rev Clin Oncol. 2015;12:408-24

10. Torre LA, Bray F, Siegel RL, Ferlay J, Lortet-Tieulent J, Jemal A. Global cancer statistics, 2012. CA Cancer J Clin. 2015;65:87-108.

11. Torrecilla $\mathrm{S}$, Llovet JM. New molecular therapies for hepatocellular carcinoma. Clin Res Hepatol Gastroenterol. 2015;39:S80-5.

12. Llovet JM, Ricci S, Mazzaferro V, Hilgard P, Gane E, Blanc J-F, et al. Sorafenib in advanced hepatocellular carcinoma. N Engl J Med. 2008;359:378-90.

13. Bruix J, Qin S, Merle P, Granito A, Huang Y-H, Bodoky G, et al. Regorafenib for patients with hepatocellular carcinoma who progressed on sorafenib treatment (RESORCE): a randomised, double-blind, placebo-controlled, phase 3 trial. Lancet. 2017:389:56-66.

14. Kudo M, Finn RS, Qin S, Han K-H, Ikeda K, Piscaglia F, et al. Lenvatinib versus sorafenib in first-line treatment of patients with unresectable hepatocellular carcinoma: a randomised phase 3 non-inferiority trial. Lancet. 2018;391: 1163-73.

15. Grant TJ, Bishop JA, Christadore LM, Barot G, Chin HG, Woodson S, et al. Antiproliferative small molecule inhibitors of transcription factor LSF reveal oncogene addiction to LSF in hepatocellular carcinoma. Proc Natl Acad Sci U S A. 2012;109:4503-8.

16. Rajasekaran D, Siddiq A, Willoughby JLS, Biagi JM, Christadore LM, Yunes SA et al. Small molecule inhibitors of Late SV40 Factor (LSF) abrogate hepatocellular carcinoma (HCC): evaluation using an endogenous HCC model. Oncotarget. 2015;6:26266-77. 
17. Willoughby JLS. Transcription factor LSF: a mitotic regulator in hepatocellular carcinoma. PhD thesis, Boston University; 2016.

18. Shlomai A. Targeting late SV40 factor: is the achilles heel of hepatocarcinogenesis revealed? World J Gastroenterol. 2012;18:6709-11.

19. Dunker AK, Uversky VN. Drugs for 'protein clouds': targeting intrinsically disordered transcription factors. Curr Opin Pharmacol. 2010;10:782-8.

20. Santhekadur PK, Rajasekaran D, Siddiq A, Gredler R, Chen D, Schaus SE, et al. The transcription factor LSF: a novel oncogene for hepatocellular carcinoma. Am J Cancer Res. 2012;2:269-85.

21. Akinc A, Goldberg M, Qin J, Dorkin JR, Gamba-Vitalo C, Maier M, et al. Development of lipidoid-siRNA formulations for systemic delivery to the liver. Mol Ther. 2009;17:872-9.

22. Nair JK, Willoughby JLS, Chan A, Charisse K, Alam MR, Wang Q, et al. Multivalent $\mathrm{N}$-acetylgalactosamine-conjugated siRNA localizes in hepatocytes and elicits robust RNAi-mediated gene silencing. J Am Chem Soc. 2014;136:16958-61.

23. Boveia V, Schutz-Geschwender A. Quantitative analysis of signal transduction with in-cell Western immunofluorescence assays. Methods Mol Biol. 2015;1314:115-30.

24. Powell CMH, Rudge TL, Zhu Q, Johnson LF, Hansen U. Inhibition of the mammalian transcription factor LSF induces S-phase-dependent apoptosis by downregulating thymidylate synthase expression. EMBO J. 2000;19:4665-75.

25. Ji J, Zhang Y, Redon CE, Reinhold WC, Chen AP, Fogli LK, et al. Phosphorylated fraction of H2AX as a measurement for DNA damage in cancer cells and potential applications of a novel assay. PLoS One. 2017;12: e0171582.

26. Yoo BK, Gredler R, Vozhilla N, Su Z, Chen D, Forcier T, et al. Identification of genes conferring resistance to 5-fluorouracil. Proc Natl Acad Sci U S A. 2009; 106:12938-43.

27. Girdler F, Gascoigne KE, Eyers PA, Hartmuth S, Crafter C, Foote KM, et al. Validating Aurora B as an anti-cancer drug target. J Cell Sci. 2006;1 19:3664-75.

28. Huang H-C, Shi J, Orth JD, Mitchison TJ. Evidence that mitotic exit is a better cancer therapeutic target than spindle assembly. Cancer Cell. 2009;16: 347-58

29. Crosio C, Fimia GM, Loury R, Kimura M, Okano Y, Zhou H, et al. Mitotic phosphorylation of histone $\mathrm{H3}$ : spatio-temporal regulation by mammalian Aurora kinases. Mol Cell Biol. 2002;22:874-85.

30. Christadore LM. Discovery of a small molecule dihydroquinolinone inhibitor with potent antiproliferative and antitumor activity results in catastrophic cell division. PhD thesis, Boston University; 2013.

31. Chin HG, Ponnaluri VKC, Zhang G, Estève P-O, Schaus SE, Hansen U, et al. Transcription factor LSF-DNMT1 complex dissociation by FQI1 leads to aberrant DNA methylation and gene expression. Oncotarget. 2016;7:83627-40.

32. Hansen U, Owens L, Saxena UH. Transcription factors LSF and E2Fs: tandem cyclists driving G0 to S? Cell Cycle. 2009;8:2146-51.

33. Hübner NC, Wang LHC, Kaulich M, Descombes P, Poser I, Nigg EA. Reexamination of siRNA specificity questions role of $\mathrm{PICH}$ and Tao1 in the spindle checkpoint and identifies Mad2 as a sensitive target for small RNAs. Chromosoma. 2010;119:149-65.

34. Goto $H$, Yasui $Y$, Nigg EA, Inagaki M. Aurora-B phosphorylates histone $\mathrm{H} 3$ at serine 28 with regard to the mitotic chromosome condensation. Genes Cells. 2002;7:11-7.

35. Ramamurthy L, Barbour V, Tuckfield A, Clouston DR, Topham D, Cunningham JM, et al. Targeted disruption of the CP2 gene, a member of the NTF family of transcription factors. J Biol Chem. 2001;276:7836-42.

36. Sadaie M, Dillon C, Narita M, Young ARJ, Cairney CJ, Godwin LS, et al. Cellbased screen for altered nuclear phenotypes reveals senescence progression in polyploid cells after Aurora kinase B inhibition. Mol Biol Cell. 2015;26:2971-85

37. Nakayama $Y$, Inoue T. Antiproliferative fate of the tetraploid formed after mitotic slippage and its promotion; A novel target for cancer therapy based on microtubule poisons. Molecules. 2016;21:663.

38. Debacq-Chainiaux F, Erusalimsky JD, Campisi J, Toussaint O. Protocols to detect senescence-associated beta-galactosidase (SA-Bgal) activity, a biomarker of senescent cells in culture and in vivo. Nat Protoc. 2009;4:1798-806.

39. Kitzen JJEM, de Jonge MJA, Verweij J. Aurora kinase inhibitors. Crit Rev Oncol Hematol. 2010;73:99-110.

40. Nair JS, Ho AL, Tse AN, Coward J, Cheema H, Ambrosini G, et al. Aurora B kinase regulates the postmitotic endoreduplication checkpoint via phosphorylation of the retinoblastoma protein at serine 780. Mol Biol Cell. 2009;20:2218-28
41. Bergers $G$, Hanahan D. Modes of resistance to anti-angiogenic therapy. Nat Rev Cancer. 2008;8:592-603.

42. von Manstein V, Yang CM, Richter D, Delis N, Vafaizadeh V, Groner B. Resistance of cancer cells to targeted therapies through the activation of compensating signaling loops. Curr Signal Transduct Ther. 2013;8:193-202.

43. Chan K-S, Koh C-G, Li H-Y. Mitosis-targeted anti-cancer therapies: where they stand. Cell Death Dis. 2012;3:e411.

44. Otto T, Sicinski P. Cell cycle proteins as promising targets in cancer therapy. Nat Rev Cancer. 2017;17:93-115.

45. Huang H-C, Sundseth R, Hansen U. Transcription factor LSF binds two variant bipartite sites within the SV40 late promoter. Genes Dev. 1990:4:287-98.

46. Small W Jr, Bacon MA, Bajaj A, Chuang LT, Fisher BJ, Harkenrider MM, et al. Cervical cancer: a global health crisis. Cancer. 2017;123:2404-12.

47. Adams D, Gonzalez-Duarte A, O'Riordan WD, Yang C-C, Ueda M, Kristen AV, et al. Patisiran, an RNAi therapeutic, for hereditary transthyretin amyloidosis. N Engl J Med. 2018;379:11-21.

48. Pasi KJ, Rangarajan S, Georgiev P, Mant T, Creagh MD, Lissitchkov T, et al. Targeting of antithrombin in hemophilia A or B with RNAi therapy. N Engl J Med. 2017:377:819-28.

49. Huang Y. Preclinical and clinical advances of GalNAc-decorated nucleic acid therapeutics. Mol Ther Nucleic Acids. 2017;6:116-32.

50. Shi B, Abrams M, Sepp-Lorenzino L. Expression of asialoglycoprotein receptor 1 in human hepatocellular carcinoma. J Histochem Cytochem. 2013;61:901-9.

\section{Publisher's Note}

Springer Nature remains neutral with regard to jurisdictional claims in published maps and institutional affiliations.
Ready to submit your research? Choose BMC and benefit from:

- fast, convenient online submission

- thorough peer review by experienced researchers in your field

- rapid publication on acceptance

- support for research data, including large and complex data types

- gold Open Access which fosters wider collaboration and increased citations

- maximum visibility for your research: over $100 \mathrm{M}$ website views per year

At BMC, research is always in progress.

Learn more biomedcentral.com/submissions 